\title{
Implementation of Multi-Modular Converter with Droop characteristics for High Speed Railway Traction System
}

\author{
Venkatasupura Vemulapati ${ }^{1}$, Dr. Y. N. Vijaykumar ${ }^{2}$ and Dr. N. Visali ${ }^{3}$ \\ ${ }^{1}$ Research Scholar, JNTUA College of Engineering/ EEE Department, Anantapur, India \\ Email: vvsupura@svcolleges.edu.in \\ ${ }^{2}$ Professor, SVCET/ EEE Department, Chittoor, India \\ Email: yn.vijaykumar@gmail.com \\ ${ }^{3}$ Professor, JNTUA College of Engineering/ EEE Department, Anantapur, India \\ Email: nvisali@gmail.com
}

\begin{abstract}
Multi Modular Converters (MMC) plays a significant role in high voltage power transmission networks due to its high scalability and modularity characteristics. MMC converters produce better efficiency \& show superiority in harmonic performance in high voltage applications like HVDC and high speed AC-Traction power supply systems. Its bidirectional operation also aided to get high installation reliability comparatively. The complicated power quality problems such as voltage fluctuations, Harmonic issues and reactive power problems of railway tracks due to the rapid movement of the locomotives need to be mitigated. The loss of speed is caused due to the neutral sections (NS) which are present throughout the power line. It is necessary that the neutral sections should be eradicated especially for high speed railway networks. In this paper, a new traction power transmission network which comprises zero NS and comparatively low power quality problems is designed. Droop control strategy is implemented to improve power transfer capability between the two adjacent traction substations. The implementation of MMC with parallel converter concept using the DSP processor is executed for low voltage as a prototype model. The results obtained are confirmed that the proposed system is very much suitable for high speed railway networks.
\end{abstract}

Index Terms: High speed traction, Parallel inverters, Droop characteristics, Indian traction power supply system.

\section{INTRODUCTION}

Public transport by electric rail is more affordable and environmentally sustainable. The electrified railway traction system is a cause of changing large nonlinear charges and polluting the electrical grid by harmonics. The balance of the phase currents and voltages is also a major problem because of the single step design of the railway interface lines network. In general, the unbalanced mechanism is a source of overloading and decreased performance [1]. Locomotives are fed by the single-phase traction transformer through catenary supply. At present Indian traction systems implement phase splitting or shifting methods for voltage balancing in each phase [2]. In phase shifting method, if the first traction substation collects power from one phase then the successive substation will collect power from another phase in sequence manner and this process repeats for each substation coming along the power line [3]. Due to this alternative phase feeding from the grid neutral sections should be placed while the locomotive crossing the first substation to next substation to avoid high inrush currents into locomotive as shown in Figure 1. Due to the existence of neutral sections power cannot be supplied to locomotive throughout the journey [4]. To dividing the system supply from electrically isolated segments, neutral segment needs to be inserted and reduces the speed promotion of highspeed trains that affects railway safety, efficiency, and growth [5]. Technical aspects like mechanical wear and tear of the equipment, safety operation and power quality issues are increases with these neutral sections [6]. Moreover, a network imbalances still exist in the traction power supply system as loads cannot be uniformly distributed across segments [7].

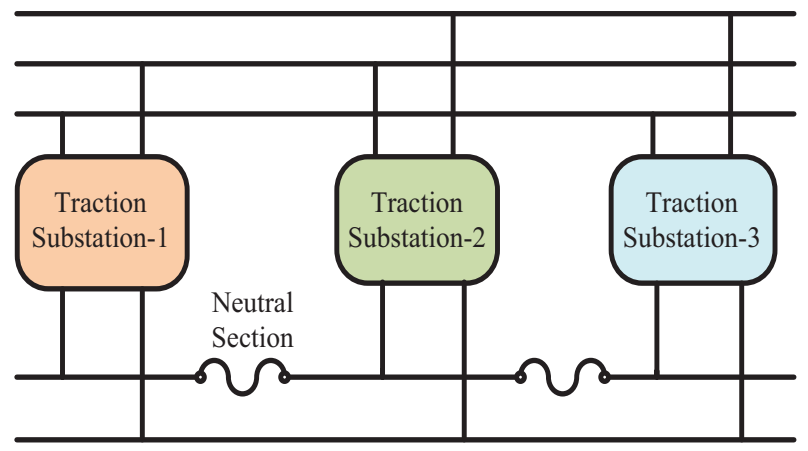

Figure 1. Indian railway phase splitting power transmission network with neutral sections

To avoid the aforementioned problems a new power delivery system is proposed which converts utility three phase grid voltage $(132 \mathrm{KV}, 50 \mathrm{~Hz})$ to single phase catenary supply voltage $(25 \mathrm{KV}, 50 \mathrm{~Hz})$ as shown in Figure 2. Modular converters are used for the power conversion [8]. A three phase rectifier and a single phase inverter is designed with the MMC converters. There are many works handled in the MMC concept that are explained in this section which made use to identify the existing problem. A new MMC converter is implemented in [9], [10]the balancing of voltage is done in this literature. A new control with PWM modulation is implemented in [11]. The DC link control and power control is done and it is implemented inthe $\mathrm{AC}$ to $\mathrm{AC}$ conversion using MMC in [12]. 


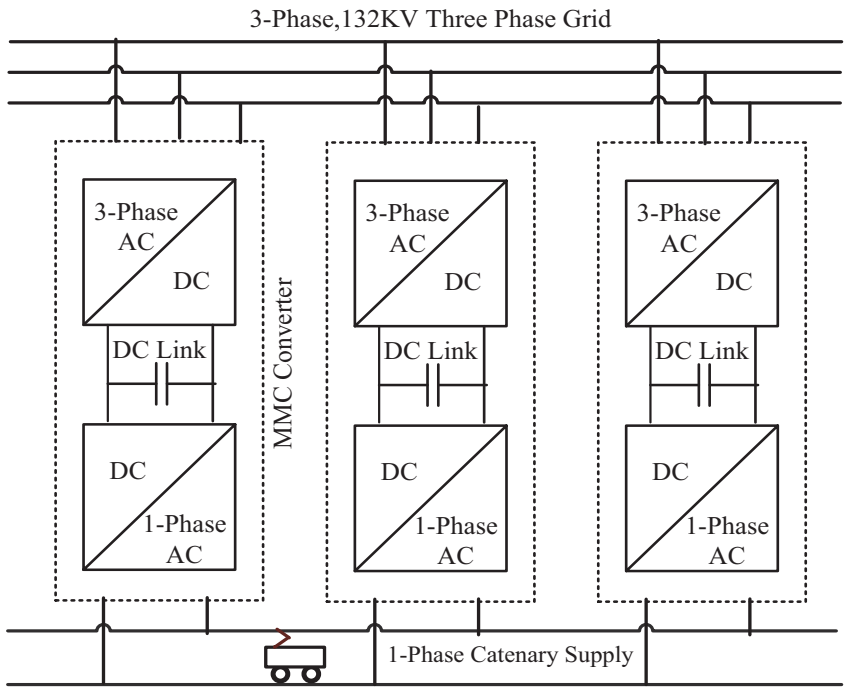

Figure 2. Proposed traction power supply network from three phase utility grid to single phase catenary with zero neutral sections.

A modular multilevel converter with huge rating is implemented as hardware in [13]. Back to back MMC with dynamic performance comparison is done in [14]. The technique of decoupling the $d$ and $q$ axis of 'abc' is presented in [15]. In this paper a newdroop control is implemented with two parallel connected MMC. The hardware circuit is implemented for $110 \mathrm{~V}$ DC. The control technique explanation is discussed in the next section.

\section{II.Proposed Droop Control Method}

Here two adjacent substations are considered for droop control. It can be assumed one as sending end and other as receiving end or both are sending ends. The MMC converter is connected at the substations and DC-link voltage is connected to the inverter at the load end [16]. The control of the inverter is droop control to make the synchronization working. The DC link control is common for both MMC $[17,18]$.

The LCL channel is utilized to constrict high recurrence exchanging clamor. Signs like the voltage and current taken from the LCL channel are changed by parks and change into direct and quadrature segments. This dq signal is utilized to ascertain the output power. A low pass channel is added after the genuine and receptive force is determined to eliminate any undesirable high recurrence signal before it is given as contribution to the hang regulator synchronization with other inverters is accomplished by contrasting the deliberate voltage and recurrence and the reference. The reference current is created from the PI regulator. This current is then contribution to other PI regulators to produce the voltage reference. A coupling inductor is utilized to couple the inverter yield. At thunderous recurrence to keep away from unsteadiness a damping resistor $\mathrm{Rd}$ is utilized. PLL dependent on the dq strategy is utilized to synchronize the recurrence with direct pivot. Symmetrical change is performed by utilizing the stage point structure the PLL. Every inverter is synchronized to its own nearby casing of reference. While there is a worldwidereference outline that would be reference of the substationl while the other inverter in substation 2 needs to change its nearby reference over to this in wider reference.

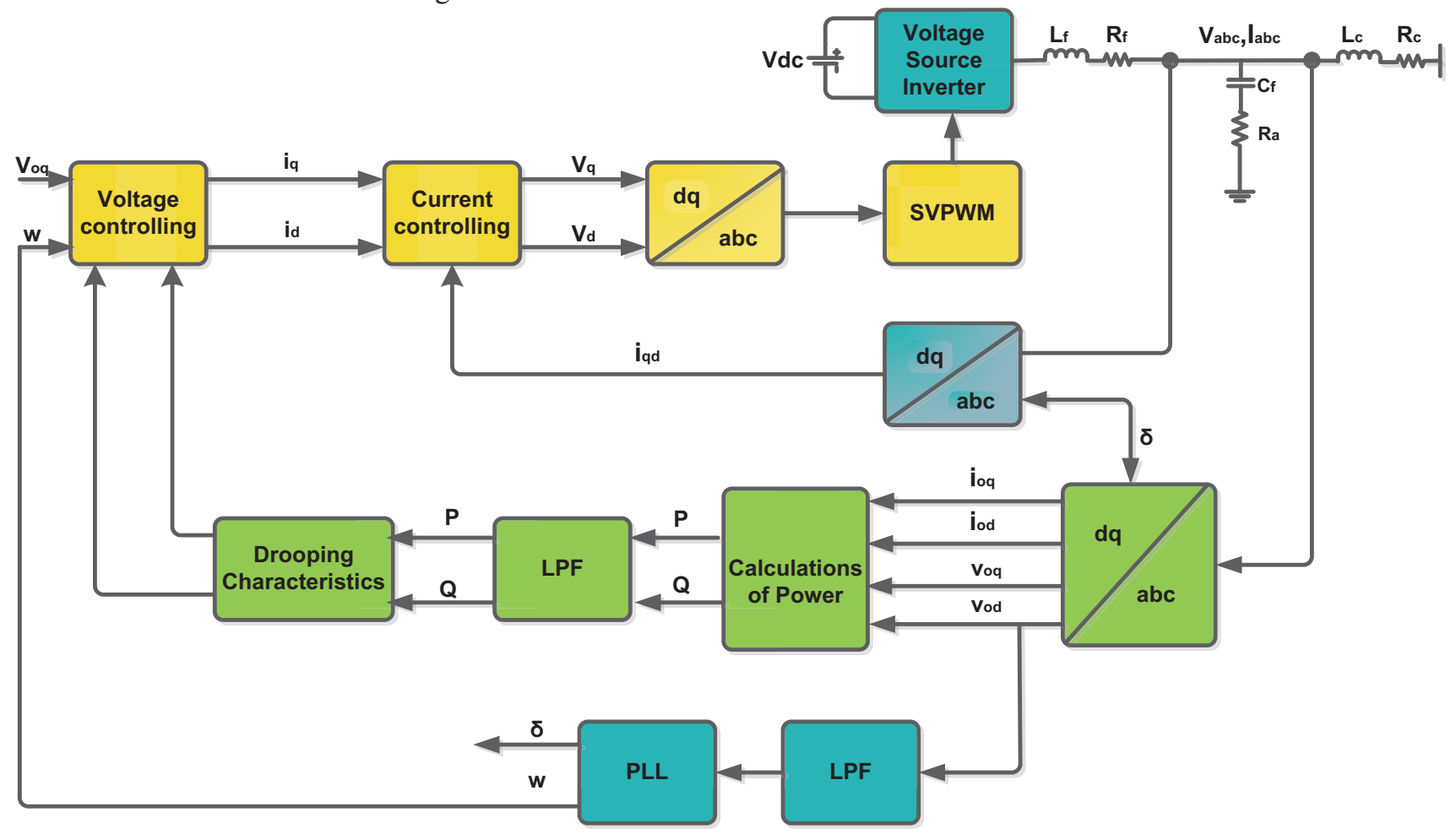

Figure 3. Self-Synchronizing Inverter with Droop Control 


\section{Estimated Voltage And Frequency}

The topology of the switching module (SM) used in the $\mathrm{MMC}$ is that of a half bridge as shown in figure 3. The SM is $\mathrm{ON}$ when T1 is ON and SM is OFF when T2 is ON. Both the MOSET's are never

ON simultaneously at any point of time or else it might lead to a short circuit.

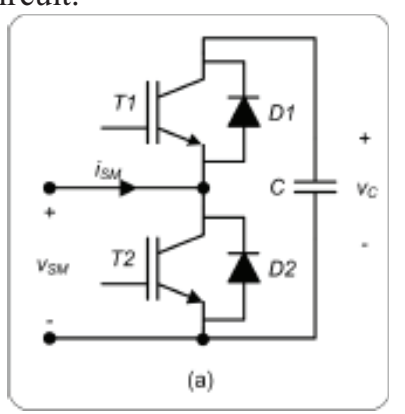

Figure 4: Switching module topology

The reference values for the angle and voltage of the inverter is set by the grid and by a PLL in the stiff grid condition. When weak grid condition occurs, the inverter has to self- synchronize using the Droop characteristics. Figure 5 (a) shows the plot of typical power and angular frequency (P$\omega)$ curve and Figure 5 (b) shows the plot of the reactive power and voltage $(\mathrm{Q}-\mathrm{V})$ curve. The reference frequency and voltage are obtained from these curves. Thus, operatingthe inverters in the self-synchronizing autonomous mode.

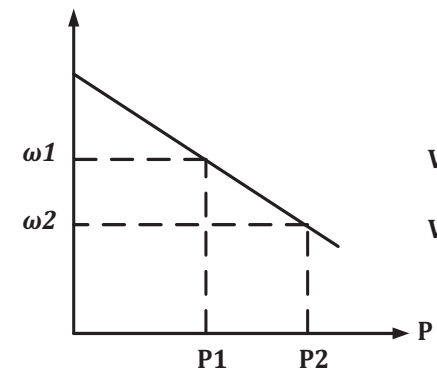

(a)

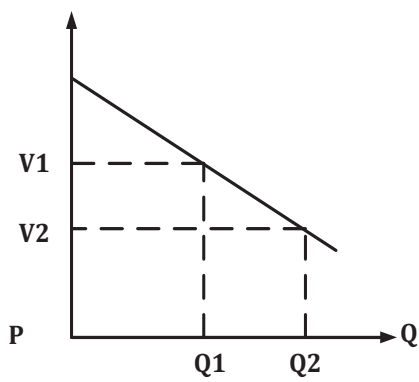

(b)
Figure 5. Droop Curves, (a) $(P-\omega)$ curve and (b) $(Q-V)$ curve

The slopes of $(P-\omega)$ curve and $(Q-V)$ curve is shown below,

$$
m=\frac{\omega_{1}-\omega_{2}}{P_{2}-P_{1}} \quad \text { And } \quad n=\frac{V_{1}-V_{2}}{Q_{1}-Q_{2}} \text {. }
$$

Droop equation equations as shown below:

$$
\begin{gathered}
\omega^{*}=\omega_{n}-m P \\
v_{o q}^{*}=V_{o q, n}-n Q
\end{gathered}
$$

The PLL is used to find the actual frequency during the autonomous condition of the AC tractionsystem. The PLL locks into the ' $\mathrm{d}$ ' component to zero.

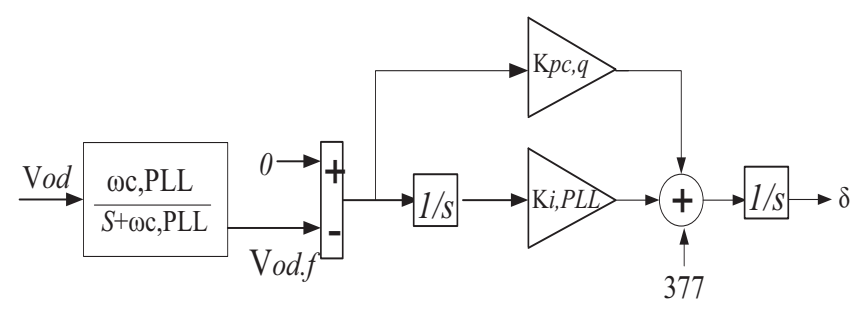

Figure 6.PLL Module.

From figure 6 the PLL is shown. It is evident that the ' $d$ ' axis component of voltageis compared with zero. This is done so to synchronize with the direct axis.

$$
\begin{gathered}
\dot{v}_{o d, f}=\omega_{c, P L L} v_{o d}-\omega_{c, P L L} v_{o d, f} \cdots \\
\dot{\varphi}_{P L L}=-v_{o d, f} \ldots \ldots \ldots \ldots \ldots \ldots \ldots \ldots \ldots \\
\delta=\omega_{P L L} \ldots \ldots \ldots \ldots \ldots \ldots \ldots \ldots \ldots \ldots \\
\omega_{P L L}=377-k_{p, P L L} v_{o d, f} \\
+k_{i, P L L} \varphi_{P L L} \cdots \cdots \cdots \cdots
\end{gathered}
$$

The voltage controller uses the set points of voltage and frequency from the droop equations. The $d q$ transformer components of the currents are given as input to the PI controller for the purpose ofgenerating in the reference line current. The control variables, angular frequency from the PLL and calculated reference angular frequency is compared as shown in. Figure 7. Similarly, the othercontrol variable 'q' component of the voltage is compared to the reference in the comparator and then given to PI controller.

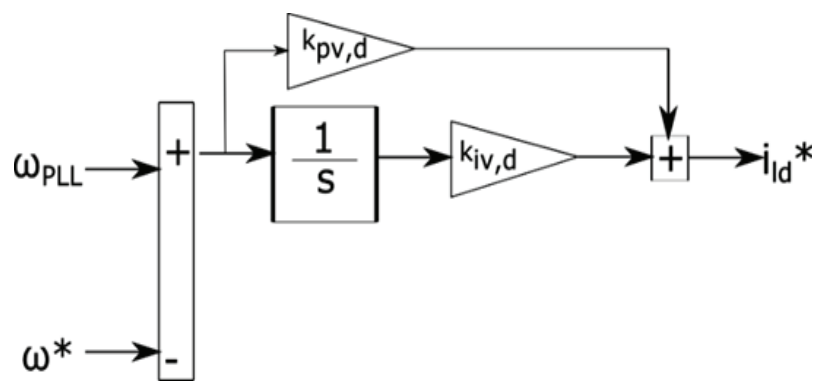

(a)

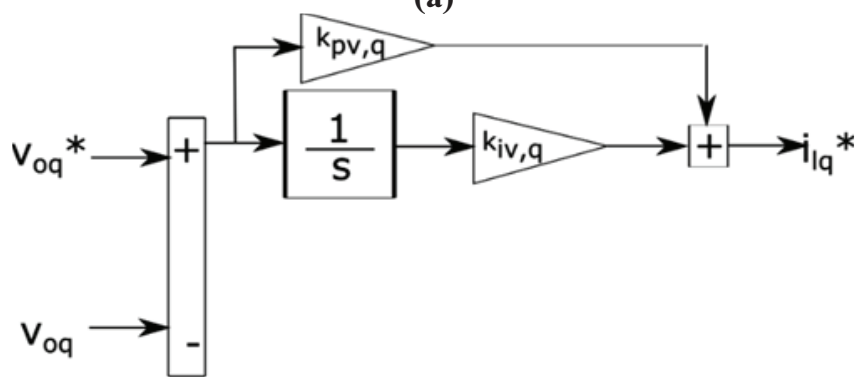

(b)

Figure 7. Voltage Controller

$$
\begin{array}{r}
\dot{\varphi}_{d}=\omega_{P L L}-\omega^{*} \\
i_{l d}^{*}=k_{i v, d} \varphi_{d}+k_{p v, d} \dot{\varphi}_{d} \ldots \ldots
\end{array}
$$




$$
\begin{array}{r}
\dot{\varphi}_{q}=v_{o q}^{*}-v_{o q} \\
i_{l q}^{*}=k_{i v, q} \varphi_{q}+k_{p v, q} \dot{\varphi}_{q} \cdots \cdots
\end{array}
$$

The reference direct and quadrature voltages are generated by the current controller. Figure 7 shows how this reference voltage generated and Figure 8 shows how this reference current generated. The control voltages $v_{i d}^{*}$ are calculated from the LCLfilter. The PI controller is used with the current controller to get the control voltages $v_{i q}^{*}$ from thecommand inductor currents $\left(i_{\mathrm{L}}{ }^{*}\right)$. These values correspond to inverter output voltage.

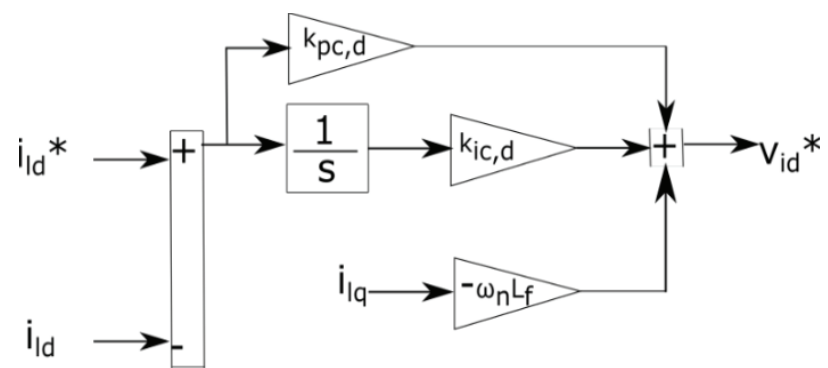

(a)

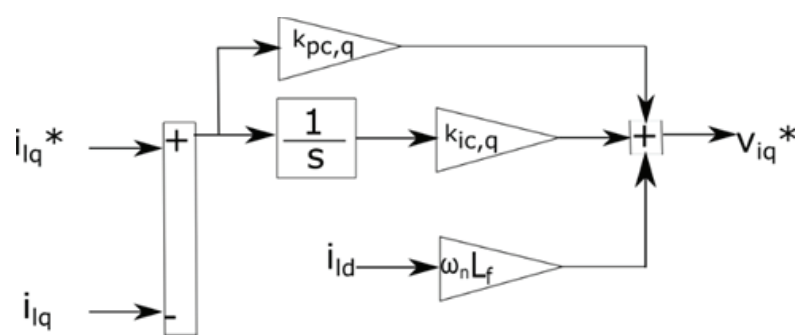

(b)

Figure 8. Current Controller

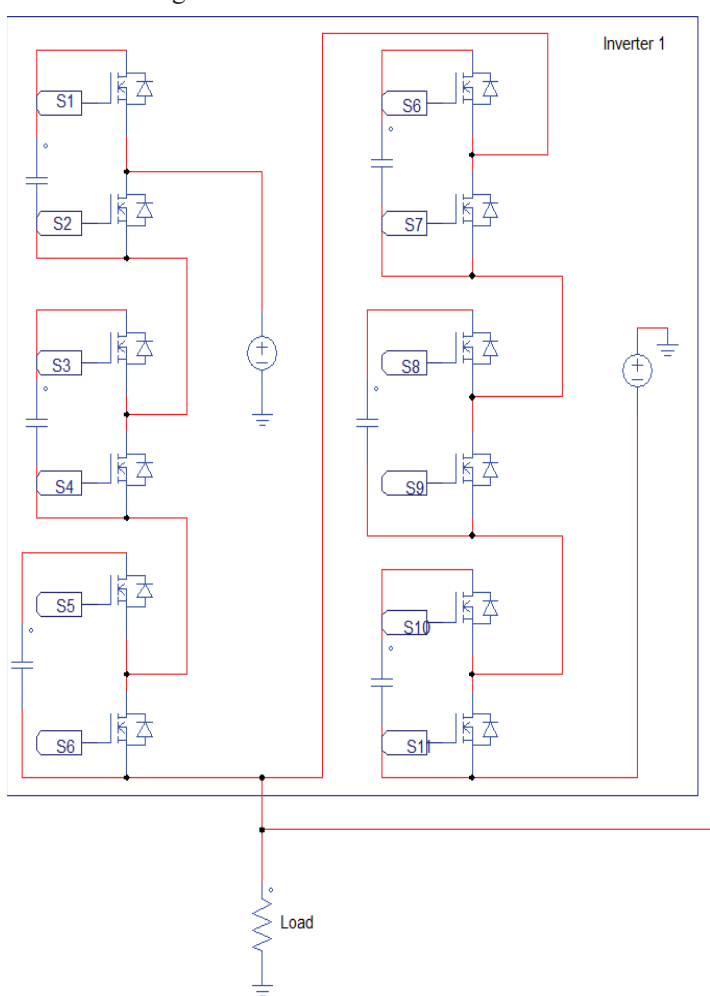

Figure 9. Design of Parallel connected MMC converter

$$
\begin{array}{r}
v_{i d}^{*}=-\omega_{n} L_{f} i_{l q}+k_{i c, d}\left(i_{l d}^{*}-i_{l d}\right) \\
+k_{p c, d}\left(i_{l d}^{*}-i_{l d}\right) \\
\begin{aligned}
v_{i q}^{*}=\omega_{n} L_{f} i_{l d} & +k_{i c, q}\left(i_{l q}^{*}-i_{l q}\right) \\
& +k_{p c, q}\left(i_{l q}^{*}-i_{l q}\right)
\end{aligned}
\end{array}
$$

The voltage commands are calculated according to the equations defined in (9) and (10).

The LCL filter consist of two inductors $L_{f}$ and $L_{c}$ having parasitic resistance $r_{f}$ and $r_{c}$ respectively. The filter capacitor $C_{f}$ along is connected in parallel along with damping resistor $R_{d}$. The equation governing the filter characteristics of the LCL filter without considering the IGBT and diodes losses are as shown below,

$$
\begin{gathered}
\dot{i_{l d}}=\frac{1}{L_{f}}\left(-r_{f} i_{l d}+v_{i d}+v_{o d}\right)+\omega_{P L L} i_{l q} \ldots \\
\dot{i_{l q}}=\frac{1}{L_{f}}\left(-r_{f} i_{l q}+v_{i q}-v_{o q}\right)-\omega_{P L L} i_{l d} \ldots . \\
i_{o d}^{\cdot}=\frac{1}{L_{c}}\left(-r_{c} i_{o q}+v_{o d}-v_{b d}\right)-\omega_{P L L} i_{o q} \ldots \\
\dot{i_{o q}}=\frac{1}{L_{c}}\left(-r_{c} i_{o q}+v_{o q}-v_{b q}\right)-\omega_{P L L} i_{o d} \ldots \\
v_{o d}^{\cdot}=\frac{1}{C_{f}}\left(i_{l d}-i_{o d}\right)+\omega_{P L L} v_{o q} \\
\quad+R_{d}\left(i_{l d} i_{o d}\right) \ldots \ldots \ldots \ldots \ldots \ldots \\
v_{o q}=\frac{1}{C_{f}}\left(i_{l q}-i_{o q}\right)+\omega_{P L L} v_{o d}+
\end{gathered}
$$

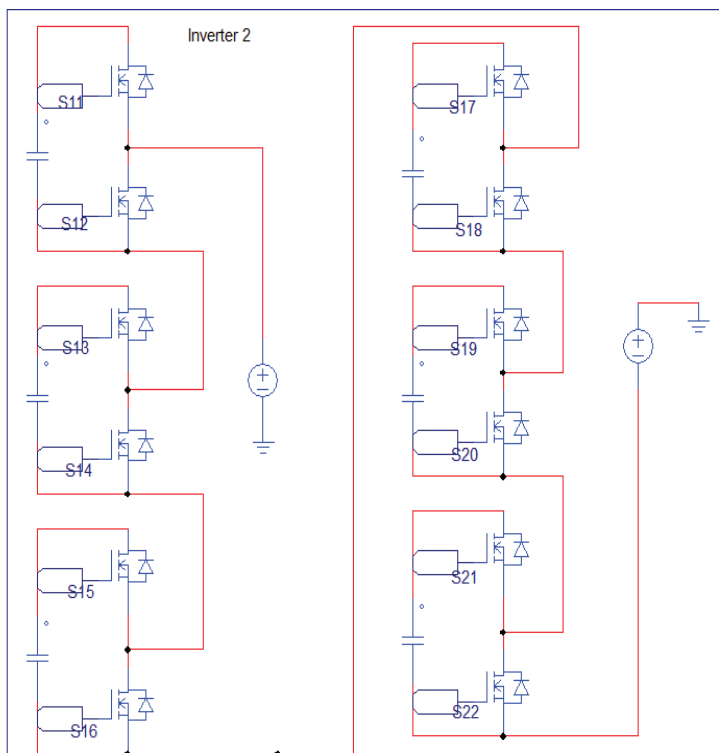


The Figure 9 shows the design of parallel connected half bridge MMC converter with total of six MMC modules per leg so that the upper arm has three MMC and lower arms have three MMC. As the result single leg it has six MMC controllers and another inverter has the same configuration. Both are in parallel to each other.

\section{Results And Discussions}

The simulation of proposed traction substation design from three phase to single phase converter controller using a multi modular converter was built. The locomotives are taken as the loads. The basic parameters considered for the simulation are mentioned in table 1. Two parallel incerters of traction substation are balanced with droop characteristics and DC-link voltage can be controlled. To obtain the non distorted output voltage waveform LC-filter is used. The $\mathrm{L}$ and $\mathrm{C}$ parameters are designed along with the MMC.
TABLE I.

SIMULATION PARAMETERS

\begin{tabular}{|c|c|c|}
\hline $\begin{array}{l}\text { S.N } \\
\text { O }\end{array}$ & Parameters & Value \\
\hline 1 & Three Phase grid voltage & $\begin{array}{c}132 \mathrm{kV}, 50 \\
\mathrm{~Hz}\end{array}$ \\
\hline 2 & Traction power rating & $30 \mathrm{MW}$ \\
\hline 3 & $\begin{array}{c}\text { Number of traction substations } \\
\text { considered }\end{array}$ & 2 \\
\hline 4 & No of Modules per leg in MMC structure & 3 \\
\hline 5 & Traction output Voltage & $\begin{array}{c}27.5 \\
\mathrm{kV}, 50 \mathrm{~Hz}\end{array}$ \\
\hline 6 & Frequency of carrier wave & $1 \mathrm{kHz}$ \\
\hline
\end{tabular}

The existing indian traction power system with the input voltage of $132 \mathrm{KV}$ is given as input to the traction substation and same voltage and power ratings are considered for this simulation. The Grid side voltage and current waveforms are displayed in figure 10 .
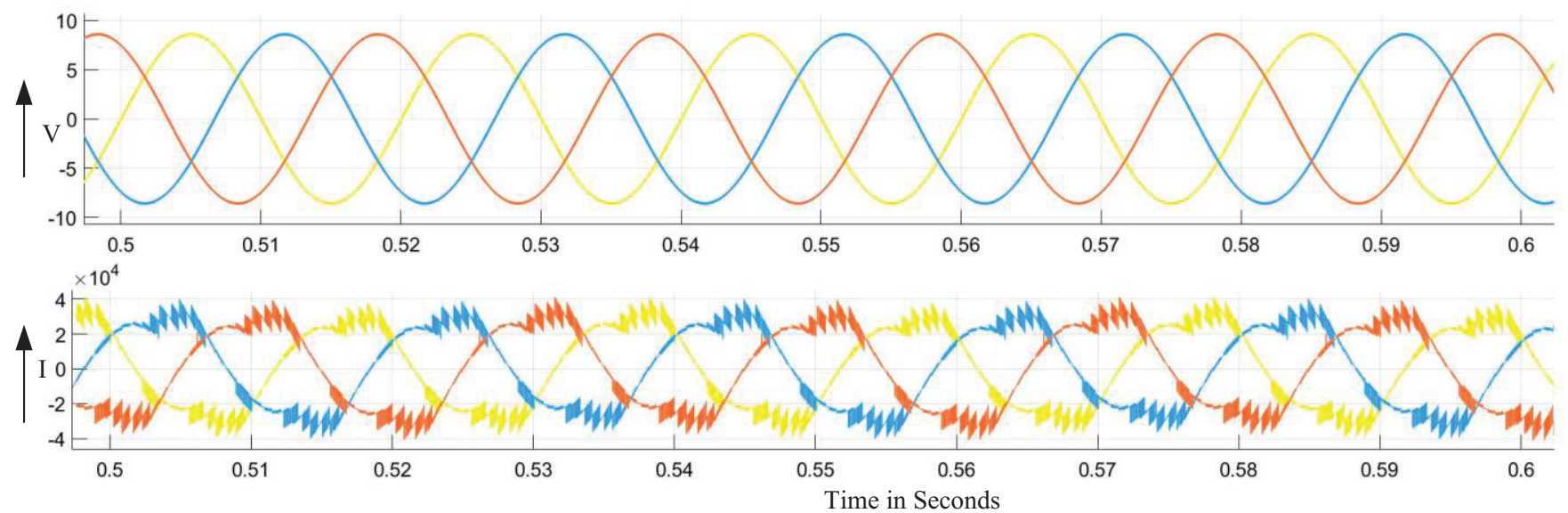

Figure 10. Three phase utility grid voltages

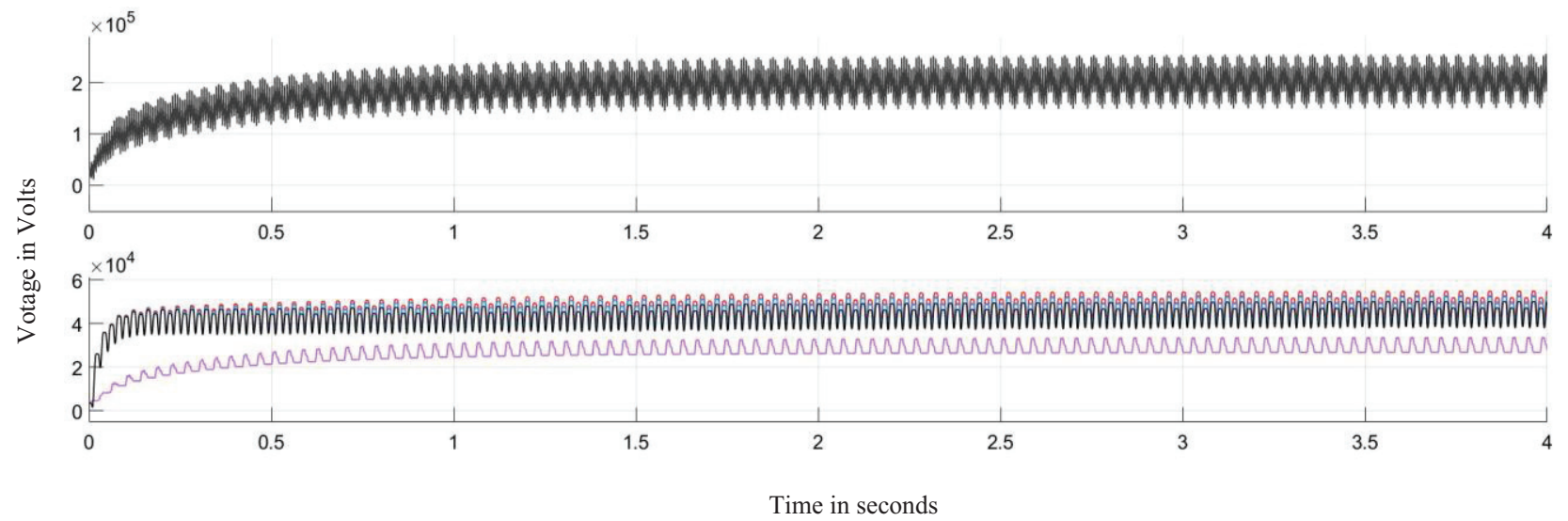

Figure 11. DC-Link Voltage waveform 


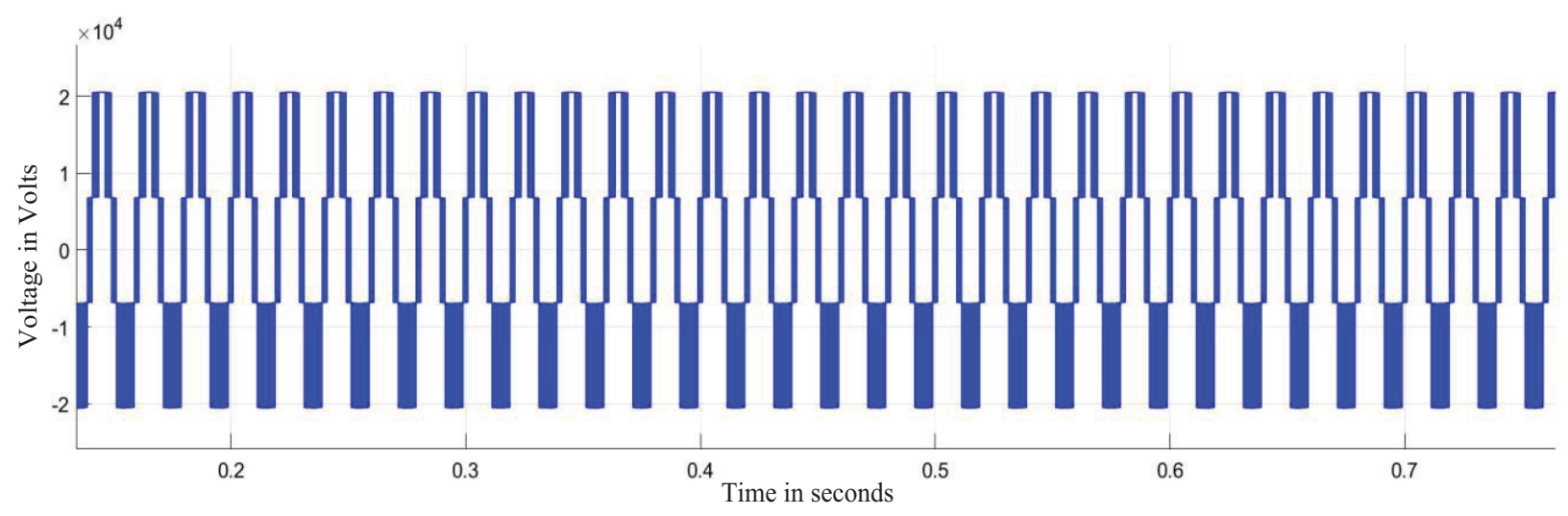

Figure 12: Single Inverter Output voltage

The DC Link capacitor has to be balanced for back back operation in MMC Converter and voltage waveform is shown in Figure 11.The output of the parallel inverter voltage is represented in the Figure 12.

\section{Conclusions}

The main application of the MMC is for high voltage transmission, although it has also been used in other applications such as the distribution static synchronous compensator and electrical traction. A very important application is the connection of offshore wind farms to the transmission grid. End stations can be synchronized using communication systems or work independently following specific rules. Here the droop control is implemented in the DSP processor and the results are analyzedwith the input of $110 \mathrm{~V}$ DC at the DC point. The hardware implementation of MMC for a single phase with the DSP controller is employed and the programming to the converter is done using the embedded coder in MATLAB. The procedure with circuit and outputs are explained in this paper. The results obtained for the proposed method are satisfactory.

\section{REFERENCES}

[1] V.Vemulapati, Y. N. Vijayakumar and N. Visali, "Droop Characteristics based High Speed Traction Power Supply system using Modular Multilevel Converter," 2020 4th International Conference on Trends in Electronics and Informatics (ICOEI)(48184), Tirunelveli, India, 2020, pp. 111118, doi: 10.1109/ICOEI48184.2020.9142920.

[2] Y. N. Vijaykumar, V. Vemulapati, N. Visali and K. Raju, "Railway Power Supply System using Modular Multilevel Converter with Droop Characteristics," 2020 4th International Conference on Electronics, Communication and Aerospace Technology (ICECA), Coimbatore, 2020, pp. 12-20, doi: 10.1109/ICECA49313.2020.9297599.

[3] K. Wang, Y. Li, Z. Zheng," Voltage Balancing Control and Experiments of a Novel Modular Multilevel Converter" in Energy Conversion Congress and Exposition (ECCE), pp.36913696, 2010

[4] L. Zhang, G. Wang," Voltage Balancing Control of a Novel Modular Multilevel Converter" in Proc. 4th int. Conference Electric Utility Deregulation and Restructuring and Power Technologies (DRPT), pp.109-114, 2011
[5] M. Hagiwara, H. Akagi," Control and Experiment of Pulsewidth-Modulated Modular Multilevel Converters" IEEE Transactions on Power Electronics, vol. 24, no. 7, pp. 17371746, Jul. 2009

[6] M. Vasiladiotis, S. Kenzelmann, N. Checrix, A. Rufer," Power and DC Link Voltage Control Considerations for IndirectAC/AC Modular Multilevel Converters" 14th European Conference on Power Electronics and Applications Conference (EPE), Birmingham, UK, Aug.-Sept. 2011

[7] S. Rohner, S. Bernet, M. Hiller, and R. Sommer," Analysis and Simulation of a $6 \mathrm{kV}, 6 \mathrm{MVA}$ Modular Multilevel Converter" in Proc. IEEE Industrial Electronics Annual Conference (IECON), Bari, Porto, Portugal, pp. 225-230, 2009

[8] M. Saeedifard, R. Iravani," Dynamic Performance of a Modular Multilevel Back-to-Back HVDC System" IEEE Transactions on power delivery, vol. 25, no. 4, pp. 2903-2912, Oct. 2010

[9] H. Mohammadi P., M. Tavakoli Bina," A Transformerless Medium-Voltage STATCOM Topology Based on Extended Modular Multilevel Converters" IEEE Transactions on power electronics, vol. 26, no. 5, pp. 1534-1545, May 2011

[10] M. Glinka," Prototype of multiphase modular-multilevelconverter with 2 MW power rating and 17-level-outputvoltage" In Proc. IEEE Power Electronics Specialists Conference (PESC), Aachen, Germany, vol. 4, pp. 2572-2576, Jun. 2004

[11] L. Xiaoqian, S. Qiang, L. Jianguo, L. Wanhua," Capacitor voltage balancing control based on CPSPWM of Modular Multilevel Converter" in Energy Conversion Congress and Exposition (ECCE), pp.4029-4034, 2011

[12] G. Ding, G. Tang, Z. Hem M. Ding," New Technologies of Voltage Source Converter (VSC) for HVDC Transmission System Based on VSC" in Proc. IEEE Power Eng Soc. General Meet. Conversion and Delivery of Electrical Energy in the 21st Century, pp. 1-8 Beijing, Jul. 2008

[13] K. Ilves, A. Anthonopoulos, S. Norrga, H-P. Nee," A New Modulation Method for the Modular Multilevel Converter Allowing Fundamental Switching Frequency" Proc. IEEE 8th Int. Power Electronics and ECCE Asia (IPCE \& ECCE) Conf., pp. 991-998, 2011

[14] M. Rasheduzzaman, J.A. Mueller, J.W. Kimball, "An accurate small-signal model of inverter- dominated islanded microgrids using dq reference frame", IEEE J. Emerging Sel. Top. Power Electron. vol. 2, no. 4, pp. 1070-1080, 2014.

[15] G.T. Son, H.J. Lee, T.S. Nam, Y.H. Chung, U.K. Lee, S.T. Baek, K. Hur, J.W. Park,” Design and Control of a Modular Multilevel HVDC Converter with Redundant Power Modules for Noninterruptible Energy Transfer" IEEE Transactionson power delivery, vol. 27, no. 3, pp. 1611-1619, Jul. 2012117 References

[16] A. Lescinar, R. Marquardt," An Innovative Modular Multilevel Converter Topology Suitable for a Wide Power Range"in Proc. 
IEEE Power Tech. Conference, Bologna, Italy, vol. 3, Jun. 2003

[17] A. Anthonopoulos, L. Angquist, H.P. Nee," On Dynamics and Voltage Control of the Modular Multilevel Converter" inProc. 13th European Conf. on Power Electronics and Applications, Barcelona, Spain, pp. 1-10, Oct. 2009.

[18] Venkatasupura Vemulapati et al. Prototype model for high speed railwaypower supply system suitable for indian traction sub stations using multimodular converter.Turkish Journal of Computer and Mathematics Education (TURCOMAT), 12(10):7211-7222, 2021. 